\title{
Variation in maternal solitary bee nest defence related to nest state
}

\author{
Jason H. Peterson ${ }^{1}$, Thomas S. HoffmeIster ${ }^{2}$, Bernard D. RoitberG ${ }^{3}$ \\ ${ }^{1}$ Biology, University of Alberta Augustana, Camrose, Alberta, Canada T4V 2R3 \\ ${ }^{2}$ Institute of Ecology and Evolutionary Biology, Universität Bremen, Leobener Str. NW2, B4040, 28359, Bremen, Germany \\ ${ }^{3}$ Evolutionary and Behavioural Ecology Research Group, Department of Biological Sciences, Simon Fraser University, \\ Burnaby, British Columbia, Canada V5A 1S6
}

Received 3 March 2015 - Revised 4 June 2015 - Accepted 26 June 2015

\begin{abstract}
Parental protection of offspring is found in numerous animal species. Protection provides offspring with a greater chance of surviving to be able to reproduce, while at the same time, often posing a cost to the parent. Therefore, the net value of defence for the parent can vary depending on the developmental stage of the offspring and their ability to defend themselves. For example, in commonly studied organisms (e.g. birds), defence level increases over time until offspring are able to leave the nest and parental defence wanes. We examine these nest defence decisions in the solitary bee system that poses an interesting variation to traditionally studied organisms. Nest value does not increase in a simple additive manner as offspring are added to the nest. Here, individual investments are allocated to each offspring, then as a final act, the nest entrance is sealed. This sealing action provides increased protection for all developing offspring in the nest, therefore strongly increasing their value. Our observational experiment using Megachile rotundata found that mothers slightly increased nest defence as nest size increased. However, unlike traditionally studied organisms, this increase in defence continued until the nest was completed.
\end{abstract}

\section{Megachile rotundata / nest defence / variable defence level / offspring provisioning state / solitary bee}

\section{INTRODUCTION}

Parental protection is required for offspring survival in numerous animal species (Archer 1988; Clutton-Brock and Godfray 1991; Hunt et al. 2007; Miller et al. 2011; Gilbert 2014; Sibbald and Plowright 2015). This protection is generally risky for parents, resulting in a trade-off between investment in current and future offspring (Trivers 1972; Dawkins and Carlisle 1976; Blancher and Robertson 1982; Nealen and Breitwisch 1997; Olendorf and Robinson 2000; Hendry et al. 2004; Morales et al. 2012). Current offspring value is therefore likely to influence

Corresponding author: J. Peterson, jpeterso@ualberta.ca

Handling Editor: Stan Schneider parental decisions on risky or energetically costly offspring defence (reviewed in Montgomerie and Weatherhead 1988; Redondo 1989; Rytkönen et al. 1995). In fact, nest defence has been shown to be flexible and sensitive to variation in offspring value (Sergio and Bogliani 2001; Dassow et al. 2012; Hardy et al. 2013).

Parents in a wide range of species have been shown to alter defence decisions based on offspring age (Montgomerie and Weatherhead 1988), brood size (Koskela et al. 2000; Olendorf and Robinson 2000), re-nesting potential (Barash 1975), potential nest value (Patterson et al. 1980) and also the current state of the nest (Carlisle 1985; Curio 1987; Winkler and Wilkinson 1988). In general, parental defence increases over time as offspring develop and where there is an increasing likelihood that progeny will survive to produce offspring of their own (Redondo and Carranza 1989). Thus, parents should be increasingly willing 
to defend their offspring asset as the asset value of the offspring increases over time (see Clark's Asset Protection Principle - Clark (1994)). On the other hand, an offspring's chance of unassisted survival often increases later in development, and when this occurs, parental investment in defence decreases (Montgomerie and Weatherhead 1988). Brood and nest defence follow patterns (Figure 1) similar to defence of individual offspring, and this general trend can be seen across numerous groups such as mammals, birds and hymenoptera (Breed et al. 2004; Caro 2005; Dassow et al. 2012).

While nest defence research has often focused on birds and social bees (eg., Roubik 2006; Goubault et al. 2007), solitary bees offer unique opportunities to evaluate nest defence hypotheses without the confound of changing nestling value and self-defence. Here, parental fitness is gained from individually allocating pollen and nectar resources to each offspring sequentially (Neff 2008), but then further increasing the value of all offspring at nest completion by capping (i.e. plugging, sealing or closing) the entrance to the nest and protecting all the offspring therein. These temporally isolated offspring receive a large increase in protection from a sudden single nest-capping event in a clear-cut, easily quantifiable manner. Situations where organisms complete parental investment with some type of protective shield are found in a number of taxa (e.g.
Stokes and Boersma 1998; Bourgeois and Vidal 2007; Dejean et al. 2012). By contrast, in many other systems, nestling vulnerability changes slowly and continuously with age and between offspring (Caro 2005) making interpretation of nest defence difficult because multiple factors may co-vary during that time.

Megachile rotundata (Fabricius), also known as the alfalfa leafcutter bee, is a solitary, gregarious, cavity-nesting, leaf-cutting bee native to southeastern Europe and southwestern Asia (Kemp and Bosch 2000). This leafcutter bee was accidently introduced to the eastern USA in the 1930s and then intentionally introduced into Canada in 1962 for the purpose of alfalfa (Medicago sativa) pollination (Hobbs 1972). $M$. rotundata has accumulated hundreds of generalist parasites, predators and nest destroyers; however, like many introduced species, they are without specialist parasites or predators (Eves et al. 1980; Waters et al. 1980; Pitts-Singer and Cane 2011).

Female $M$. rotundata bees build nests in pre-existing cavities such as beetle burrows in trees (Richards 1984). Females complete all work; males are only involved in mating, normally with one male fathering all the daughters of a mother's nest (Blanchetot 1992); sons are haploid.

This central-place-foraging alfalfa leafcutter bee requires multiple trips to obtain resources a

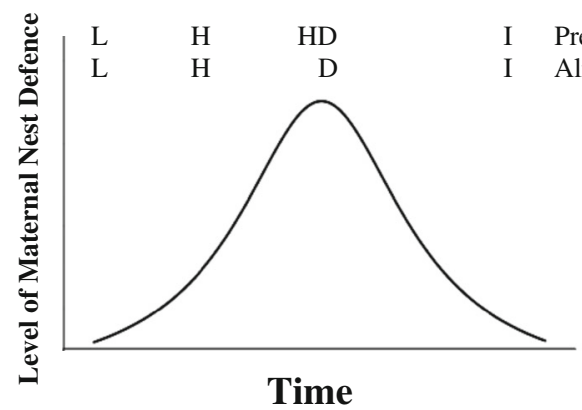

b

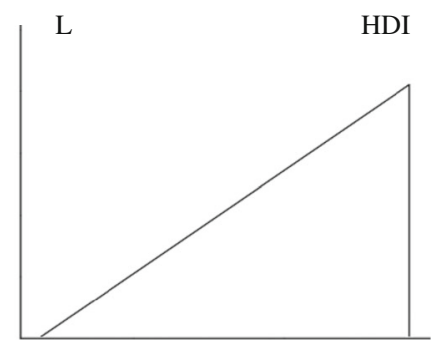

Time

Figure 1. Defence level of maternal nest for a mother at incubation or nest provisioning: a traditionally studied species such as nesting birds and mammals (key developmental points for birds included, i.e. $L$ egg-laying, $H$ hatching, $D$ nest departure, $I$ age of independence), with curve based on empirical measurements (Montgomerie and Weatherhead 1988). b Hypothesized for the experimental Megachile rotundata and many solitary bees with capping/extra production (nest sealing). 
necessary to build a nest (Orians and Pearson 1979; Schoener 1979). Such bees exploit a number of disparate resources that must be collected separately and brought to a single location to facilitate nest construction. These resources include materials to line the nest and brood cell, pollen and nectar; the latter two are sealed into the brood cell and control adult progeny size (Klostermeyer et al. 1973). The costs of obtaining these resources are expected to vary temporally and/or spatially (Parker and Frohlich 1985; Minckley et al. 1994).

Alfalfa leafcutter bees ( $M$. rotundata) may spend time and energy protecting their nest for reasons beyond the previously mentioned parasites, predators and nest-destroying species (Eves et al. 1980; Waters et al. 1980; Pitts-Singer and Cane 2011). Megachilidae are also among the bees known to not only usurp conspecific nests but sometimes remove the current brood cells of other bees before constructing their own brood cells (Field 1992). This behaviour has been recorded in our study group, Megachile spp. (Gerber and Klostermeyer 1970; Field 1992; Peterson and Roitberg, unpubl. data). Therefore, mothers have the potential of losing not only their nesting site but occasionally some or all of their completed brood cells in their nest.

Nest defence traditionally increases as the size and value of the nest rise then slowly decreases (Figure 1a) as offspring increases their ability to self-defend and/or avoid predator attacks (Redondo and Carranza 1989). Within the subgroup of solitary bees that seal their nest, however, we hypothesize that the mother will continue to increase her defence until the nest cap is completed or near-completed at which point nest defence is expected to cease. This maternal fitness benefit in solitary bees that nest capping provides is expected to alter the shape of Figure 1a to give the asymmetric defence curve Figure 1b. Mothers defend their nest through both encounters with attackers via "personal defence" and protect the nest with a cap via "capping defence". Once the capping has occurred, the marginal returns from active defence are very low (analogous to mature nestlings), so active defence should rapidly fall off. We tested our hypothesis by simulating conspecific attacks on $M$. rotundata with a model intruder bee using nests at various stages of completion. These simulations were designed to emulate conspecific nest attacks that we observed (by video) in the same area where our experiments were conducted.

\section{MATERIALS AND METHODS}

\subsection{Simulated nest attacks}

We worked with the gregarious alfalfa leafcutter bees (M. rotundata) at 40 large, communal nest sites (40,000 bees per site) to conduct an observational experiment. Simulated attacks on individual's nests were conducted between July 21 and 27, 2009 near Tilley, Alberta, Canada $\left(50^{\circ} 22^{\prime}\right.$ North, $111^{\circ} 40^{\prime}$ West $)$ between 11:00 and 16:00, at times when the temperature was above $24{ }^{\circ} \mathrm{C}$ and bees were active. M. rotundata mothers nesting in commonly used commercial laminate wood domiciles ( $8 \mathrm{~cm}$ deep and $5 \mathrm{~mm}$ diameter) were "attacked" using dried $M$. rotunda females attached to a flexible wire, a new dried female of similar size was used at each site to avoid any allelochemical effects. The simulated intruder bee was "flown" on a flexible rod into the randomly selected nesting cavity and manipulated to make repeated physical contact with the nesting female, in the same manner as natural attacks observed and analysed via videotape (Gerber and Klostermeyer 1970). All 40 nest sites had been used for at least 50 years; sites without previous use are avoided by mothers (personal observ.) and been treated with a standard bleaching process.

To prepare for this simulation on July 14 and 15 , two commercial laminate wood domicile nesting sites from the same field as the experiment was conducted were videoed (30 nesting per site) for 2 days. This same process was carried out in one domicile in a similar field, but where nesting sites were limited as a result of a higher concentration of females filling up most of the available sites. At the end of the 2 days, all the video was evaluated and the occurrence of conflict at nest sites was described and length of conflict timed.

This recorded behaviour of the attacks allowed us to successfully simulate an attack from a conspecific and response from the resident female. The flexible rod described above allowed the attacked female to push our simulated attacker out of the nest in a manner mimicking that recorded in our videos for natural attacks. For these simulated attacks, we recorded the time 
from initial contact with the simulated bee intruder to the point at which the mother bee abandoned the nest; however after $5 \mathrm{~min}$, a significant number of females just starting their nest cap remained, while the attacks on all bees from the three other situations had long ended. Based on these data, we chose $60 \mathrm{~s}$ as the termination criterion because after dissecting the attacked nest site, we found that nearly all attacks with durations longer than $60 \mathrm{~s}$ were in situations where mothers were just starting the cap. After each attack was complete, we moved to a new nesting site (at least $100 \mathrm{~m}$ away) and randomly selected a new nest to attack. This procedure avoided any cumulative impact of attacking nests of neighbouring mothers of this gregarious species. Further, we predetermined the acceptance criteria that any small-by-appearance bee (Peterson and Roitberg 2006), rare individuals less than half the size of an average female, or apparently injured individuals would be removed from analysis.

Within our experiment, we used a simulated attack with a dried conspecific bee based on field-recorded conflicts; nonetheless, we cannot be certain whether the mother responded to what she perceived as a conspecific attack or a foreign, potential predator. However, our protocol is appropriate either way because we used it to elucidate the defence activities of a mother bee based on attacks, in general, on her nest. Once the simulated attack ended, the nest was immediately dissected. We measured the current length of the nest, the number of completed brood cells, the length of any uncompleted cells and/or the length of any cap that was under construction (Figure 2).

\subsection{Data analysis methods}

Since defence times of bees were right-censored in 114 of 419 cases wherein bees did not abandon the nest within the 60-s observation time, we used survival analysis in R 2.10.0 (R Development Core Team 2009) to test nest state-dependent differences in the defence times of bees. We compared tests with an exponential data distribution (assuming a constant probability per unit time to leave the patch) and a Weibull distribution (assuming an increasing leaving tendency across time) and finally used a Weibull distribution because of its better fit to the data.

To help development nest states for our generalized linear models (Figure 3), the relationship between nest cap construction time and nest size was measured.
I.

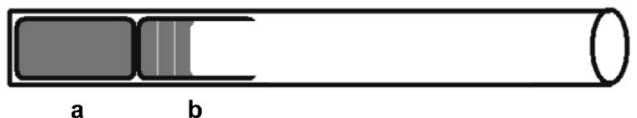

a

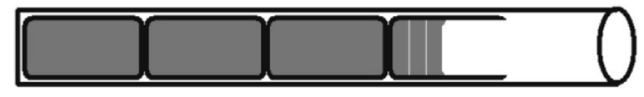

a

b

III.

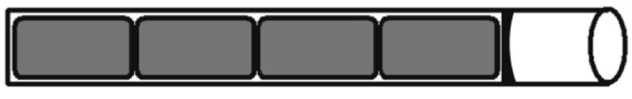

a

c

IV.

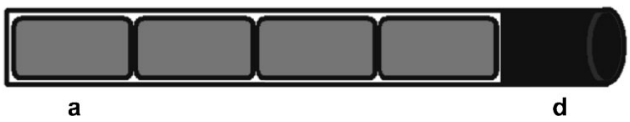

Figure 2. We divided the nests of the mothers that were attacked into four categories based on the state of their nest's construction at the time of attack (these are examples to show the features of the nest; there can be 10 or more brood cells in a single nest): (I) new nest ( $\leq 3.5 \mathrm{~cm}$ of brood cells); (II) advanced nest ( $>3.5 \mathrm{~cm}$ of brood cells produced, but no cap); (III) cap construction initiated (cap $<5 \mathrm{~mm}$ deep); and (IV) completing cap (cap $\geq 10 \mathrm{~mm}$ deep). The parts of the nest considered are a completed brood cell, $\mathbf{b}$ brood cell under construction, $\mathbf{c}$ cap under construction, $\mathbf{d}$ near completed cap.

Thirteen nests were videotaped during the entire nest capping process. The time spent collecting leaves and using them to build the cap was recorded. Upon completion of the cap, the nest was dissected to measure the size of each cap. This information aided in the development of the nest states for the generalized linear models.

At the end of the season, 40 fully capped nests, which had not been subjected to simulated attack, were randomly chosen and dissected to determine the average length $(\mathrm{mm})$ of caps in completed nests. This allowed us to determine the cap sizes that were in early versus late stages of construction during our simulated attack. We chose nests that were in close proximity to the attacked nests to remove any possible micro-site effects. These 40 fully capped nests resulted in only one cap that was less than $5 \mathrm{~mm}$ in depth and 36 that where equal to or greater than $10 \mathrm{~mm}$. Therefore, we defined nests with a cap less than $5 \mathrm{~mm}$ as cap construction initiated and nests having a cap equal to or greater than $10 \mathrm{~mm}$ as completing cap (leaf pieces were still being added).

We divided the mothers that were attacked into four categories based on the state of their nest's construction at the time of attack (Figure 2): (I) new nest ( $\leq 3.5 \mathrm{~cm}$ of 


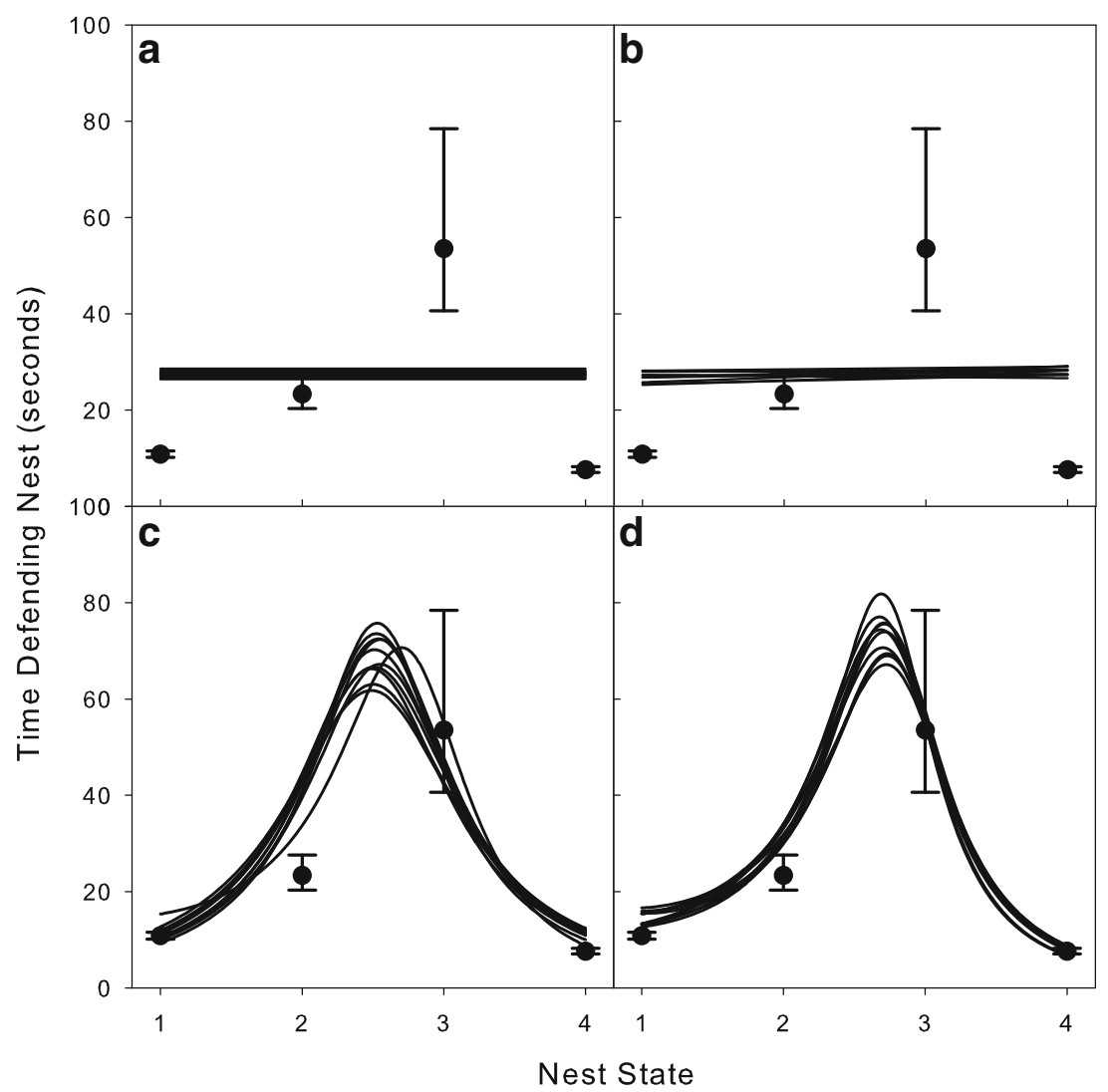

Figure 3. Nest defence intensity of solitary leafcutter bees across the four nest states as defined in Figure 2. Nest states III and IV both occur near the end of nest construction. Solid circles represent arithmetic means for experimental data. The solid lines represent trend analyses for 10 randomly drawn gamma distributed data sets with 100 data points for each nest state using generalized linear models with gamma distribution and inverse link function. a Nest defence that is insensitive to nest state, estimating the intercept; $\mathbf{b}$ linear models for nest defence as a function of nest state; $\mathbf{c}$ quadratic models and $\mathbf{d}$ cubic models. (See text for the fit of the respective models to the data sets; cubic is the best fit statistically).

brood cells), (II) advanced nest ( $>3.5 \mathrm{~cm}$ of brood cells produced, but no cap), (III) cap construction initiated ( $<5 \mathrm{~mm}$ deep cap) and (IV) completing cap ( $\geq 10 \mathrm{~mm}$ deep cap). Only after the nest was dissected could we determine the state of the nest during our simulated attack. The brood cell(s) or cap length then allowed us to determine if the nest could be used; we did not use those with caps between 5 and $10 \mathrm{~cm}$ in length as described earlier. Usable nests were then allocated into one of the four nest state categories.

We also investigated the relationship between the cap size and the number of brood cells in the nest. Therefore, at the end of the season, 490 nests in the same domicile boxes as those in our simulated attack were dissected and the number of brood cells counted and the depth of the cap measured in each nest. Marking the size of these nests half way though the season helped us to identify if nests had been usurped and the old brood cells chewed out during the second half of the season.

\subsection{Generalized linear models}

Each simulated attack on a mother bee is a specific data point, which was categorized in the above work. We also wanted to evaluate the results looking at each group along a continuum to examine the shape of the defence curve as nest state increases towards completion. We compare our results to a number of possible 
generalized linear models as a test of these competing hypotheses (Figure 3):

(i) A flat line (defence level is a constant), as we might expect in a situation where offspring susceptibility is invariant with age and thus the value of the mother's defence does not change.

(ii) There is greater investment into defence with offspring age. Offspring value alone determines level of defence. Here, the mother is willing to provide higher and higher levels of defence in order to protect her increasingly valuable offspring.

(iii) Parabolic models based upon returns from defence. Here, offspring become increasingly valuable yet defenceless as they age, but at some point, there is a sudden change in value or susceptibility (e.g. offspring develop a trait after which they are able to defend themselves or become invulnerable to attacks).

As our experimental data contained censored values and can thus not be directly used for the analysis with generalized linear models, we drew 10 randomly gamma distributed data sets with 100 replicates for each of the four nest states, with shape parameter and scale based upon the standard deviation and mean, respectively, of the original data sets. We thus created 10 simulated data sets that are conservative, i.e. they underestimate the mean of nest state III and compared generalized linear models for each of the data sets fitting just the intercept, linear models, quadratic models and cubic models using Akaike values.

\section{RESULTS}

\subsection{Field observations}

The pre-experiment nest defence video recording showed that of the 30 nests per location, there were 12 and 8 actively used nesting sites in the two experimental sites during the 2 days of recording, respectively. For the one dense population site, there were 14 available nesting sites, all of which were being nested in during the 2 days of videoing (other 16 sites were already used and capped). There were five and three recorded attacks, respectively, all by conspecifics, lasting longer than $5 \mathrm{~s}$ in the experimental sites over the
2 days. At the dense population site, there were 18 attacks, all by conspecifics, over the 2 days. No males were found attacking or being attacked at nest sites; to the contrary, in the evenings, 2-10 males would spend the night together in an empty nesting site. There were no observed attacks from other species at any nesting site over the 2 days of recording.

With regards to the attacks, each are vary similar with an intruder female entering an occupied nesting cell and locking mandibles with the resident female in the nest, with the intruder trying to pull backwards and drag the resident female out of the nest. The resident would pull back to maintain her position in the nest. If the resident female was pulled completely out of the nesting site, she would leave and not immediately return. The release of the mandibles always signalled the end of the attack. All attacks lasting longer than 2 min were against females just beginning their nest cap.

Observations showed that nest usurpation followed by destruction of the previous female's cells (Field 1992) did occur. Five of the previously mentioned nest usurpations resulted in all or part of the current nest being destroyed. All but one of these events occurred in the site where nest availability was limited.

\subsection{Field tests}

The response of the resident bee to our simulated bee attack followed the pattern observed in the video recordings of natural attacks.

Nest defence continued to increase as more brood cells were constructed and as the cap construction began, before dropping dramatically near the end of cap construction. Defence times increased significantly from nest state I (new nests $<3.5 \mathrm{~cm}$ of brood cell construction) to nest state II ( $>3.5 \mathrm{~cm}$ of brood cell construction) to nest state III (cap under construction; Figure 4). Defence times then dropped and were significantly lower for nest state IV (near completed cap) than even nest state I (survival analysis with Weibull data distribution, $\chi_{3}^{2}=503.07, P<0.0001$, all contrast to nest state $\mathrm{I}, P<0.001)$.

The relationship between the cap size and time spent capping was highly significant for the 13 capping events observed (capping size $=0.541+$ 


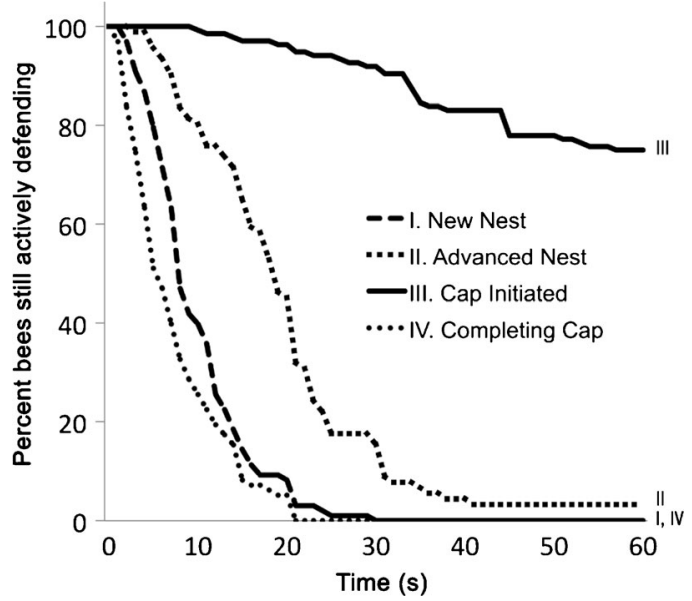

Figure 4. Plot of the time (mean $+\mathrm{SE})$ mothers actively defended their nest from a simulated attack using a dried Megachile rotunda female attached to a flexible wire. The simulated bee mimicked the videoed attacks of live females making physical contact with the jaws of the nesting female. Nest states: (I) new nest $(\leq 3.5 \mathrm{~cm}$ of brood cells) solid line; (II) advanced nest ( $>3.5 \mathrm{~cm}$ of brood cells produced, but no cap), dashed line; (III) cap construction initiated (cap $<5 \mathrm{~mm}$ deep), dotted line and (IV) completing cap ( $\geq 10 \mathrm{~mm}$ deep), dash-dotted line.

$1.49 \times$ cap time) (ANOVA: $F_{1,12}=74.35$, $P<0.0001)$ with a $R^{2}$ of 0.87 . The mean cap size $\pm \mathrm{SE}$ was $10.8 \pm 1.0 \mathrm{~mm}$. The cap size to nest size (number of cells) relationship was also significant; however, it generated a $R^{2}$ value of 0.07 from the 474 nests examined (nest size $=6.10+$ $0.15 \times$ cap size) (ANOVA: $F_{1,472}=35.7$, $P<0.0001)$.

\subsection{Generalized linear models}

A visual examination of our data and trend analysis of 10 randomly re-sampled data sets using generalized linear models with gamma distribution of data and inverse link function suggests a rising parabolic curve with a strong drop near the end (Figure 3). Models for a linear increase of defence behaviour (Figure 3b) are not significant $(P>0.25$ for all replicates $)$ and do not explain the data better than a model assuming no effect of nest state on defence (Figure 3a); Akaike values consistently and on average for the 10 replications are lower for the latter, $\mathrm{AIC} \pm \mathrm{SD}=$ $3445 \pm 17.8$ vs. $3443 \pm 17.7$. In contrast, parabolic models (Figure $3 \mathrm{c}, \mathrm{d})$ are significant $(P<0.0001)$ and always have lower Akaike values. A comparison of quadratic (Figure 3c) and cubic models (Figure 3d) suggests that cubic models with their slower increase and more rapid decline explain the data better than quadratic models; $\mathrm{AIC} \pm \mathrm{SD}=$ $3061 \pm 43.9$ vs. $3145 \pm 43.8 ; 58.7 \pm 3.1 \%$ of the deviance explained by cubic models vs. $49.5 \pm$ $4.2 \%$ for quadratic models.

\section{DISCUSSION}

Nest defence research has generally focussed on social insects, birds and mammals (Breed et al. 2004; Goubault et al. 2007; Schuett et al. 2012; Segers et al. 2015). The parental defence curve has mostly been shown to increase as the value of offspring increases and then decrease (Figure 1a) as offspring begin leaving the nest and are able to fend for themselves or are less likely to suffer harm (Montgomerie and Weatherhead 1988; Clutton-Brock 1991). Nest capping/sealing solitary bees pose an interesting variation to traditionally studied organisms, because nest value does not increase in a simple monotonic fashion over time. Instead, the one-time capping (sealing) of the nest entrance just before the mother leaves the nest provides increased protection for all developing offspring in the nest. This act increases each offspring's value, independent of any offspring behaviours as in other organisms. The size of the cap was significantly related to both the time spent building the cap and the size of the nest. In addition, this sealing act rapidly and dramatically reduces the marginal returns from any further defence of the nest.

Solitary bee mothers must readily defend their nests from conspecific attacks, conspecific nest usurpation, parasitoids and other predators (Stephen 1979; Eves et al. 1980; Rosenheim 1990; Garófalo et al. 1992). All of these occurrences are likely to result in the potential loss of offspring. Prior to sealing behaviour, we found that nest defence increased as nest size increased as generally expected. However, as the capping process begins, nest defence increases 
dramatically and then wanes rapidly when the cap is of a substantial size, approaching $10 \mathrm{~cm}$.

The survival analysis in Figure 4 illustrates, as predicted, that soon after capping is completed, defence drops to levels even lower than at early nest states. The statistical analysis of generalized linear models suggests that a cubic model explains the data best (Figure 3). Thus, the first half of the defence curve is similar to the traditional curve, but there is no gradual and symmetrical drop off in nest/offspring defence as in quadratic models, but rather, the drop off in defence intensity is much more pronounced. In our trend analyses, nest states have been spaced out evenly over time; however, it should be noted that the construction of a nest can take from 1 week to an entire lifetime ( $\sim 6$ weeks for females); thus, the time intervals between nest states I and II, and II and III are much wider than the time interval between nest states III and IV. Consequently, the curve only declines during the last hours of nest construction. Taking this into account would only influence model selection such that the relative explanatory power of cubic models over quadratic models would increase.

Our experiments used randomly chosen bees from nests in the field, and as such, there is potential for unintended bias or misinterpretation. This is highly unlikely for the following reasons. If, for example, weak or injured bees were unable to defend nests, that would generate steep survivorship curves. However, this could not explain our results of an equally steep curve for the obviously healthy bees that were just completing their nests. Second, our bees were hatched at the same time, and all were released simultaneously, at the halfway point in their life our observational experiment occurred, effectively removing any age confound. Finally, for this species (Klostermeyer et al. 1973), there is no temporal within-day bias in terms of nest or cell completion state that could bias our results. Within a single day, a given female may complete a portion of one brood cell, one cell, two cells or even three cells (Pitts-Singer, unpubl. data).

In traditionally studied species, the parental decision benefits are incremented once (e.g. when the offspring has been fledged). However, nest capping solitary bees accrue fitness first by producing offspring and later by further protecting those offspring via sealing the nest (Peterson et al. 2007). This second fitness benefit is possibly a reason for the dramatic shift in the shape of the parental defence curve.

It is also important to remember that our observations were aseasonal, with the experiment taking place over a few days and so the impact of changing seasons was unlikely to be a factor. This begs the question, for future research, of how defence behaviour may differ based on whether the nest is capped half way through the season or near the end of the season. There is also the question as to how the current sex ratio of the nest may impact defence.

There are numerous hypotheses for factors that control nest defence. These include parental investment being determined by (1) parental predation risk, (2) reproductive value of offspring (parent investment theory) and (3) the harm that unprotected offspring would suffer (Dale et al. 1996; Riou and Hamera 2008). In reality, all of these hypotheses likely apply to any species, but their relative importance varies with breeding conditions, the type of predator/attacker and current versus future reproductive value. The results from our nest capping solitary bee research support a combined version of the latter two hypotheses, i.e. reproductive value and mortality risk to offspring. These results can be seen in other Hymenoptera such as bethylid wasps which nest in parasitized hosts; as brood develop, offspring value increases while risk decreases (Bentley et al. 2009).

We have approached the nest defence trade-off as an optimization problem despite the fact that interactions between conspecifics at nest sites are more like an owner-intruder game than a simple response to background predation (e.g. Bentley et al. 2009). However, note that the result of loss to an intruder leads to possible loss of brood and as such is analogous to encounters with predators at the nest. In addition, since we fixed the behaviour of the simulated bee, we controlled for interactions between players and allowed for owner behaviour to be expressed with regard to brood value and mortality risk at a single intruder value. Should intruders escalate their attempts at nest usurpation, the outcome might change in a manner not predicted by our non-game competing hypotheses. 
Research on eusocial nest defence of offspring varies depending on conditions, with a more complex system, compared to solitary bees, of nonreproductive individuals responsible for defence (Page and Robinson 1991; Turillazzi and Hansell 1991). Here, we examined a less-well-studied situation where the value of nest defence does not taper off as offspring begin to fend for themselves but drops off suddenly once the entrance to the nest has been sealed. Bees in general are likely to have this parabolic relationship (Figure 1); however, in our solitary bee the curve is highly asymmetric compared to the slow drop over time in animals where offspring mature and gain defensive attributes. Further study of nest defence in a wider array of solitary bee taxa is likely to reveal other organisms displaying a similar defence strategy.

\section{ACKNOWLEDGMENTS}

We thank Elizabeth Elle, Dov Lank, Jay Rosenheim and David Green for discussions on this issue and Gloria Evans for editorial comments on earlier drafts. This work was supported by the Natural Sciences and Engineering Research Council of Canada through a postgraduate doctoral scholarship and operating grant.

Variation du comportement maternel de défense du nid d'une abeille solitaire, liée au stade de construction du nid

\section{Megachile rotundata / défense du nid / niveau de défense variable / état d'approvisionnement de la descendance}

Variation im Nestverteidigungsverhalten von solitären Bienen in Bezug auf den Neststatus

Megachile rotundata / Nestverteidigung / variabler Verteidigungsgrad / Ernährungszustand der Nachkommen / solitäre Biene

\section{REFERENCES}

Archer, J. (1988) The behavioural biology of aggression. Cambridge University Press, Cambridge

Barash, D.P. (1975) Evolutionary aspects of parental behavior: distraction behavior of the alpine accentor. Wilson Bull. 87, 367-373
Bentley, T., Hull, T.T., Hardy, I.C.W., Goubault, M. (2009) The elusive paradox: owner-intruder roles, strategies, and outcomes in parasitoid contests. Behav. Ecol. 20, 296-304

Blancher, P.J., Robertson, R.J. (1982) Kingbird aggression: does it deter predation? Anim. Behav. 30, 929-936

Blanchetot, A. (1992) DNA fingerprinting analysis in the solitary bee Megachile rotundata : variability and nest mate genetic relationships. Genome 35, 681-688

Bourgeois, K., Vidal, E. (2007) Yelkouan shearwater nestcavity selection and breeding success. C. R. Biol. 330, 205-214

Breed, M.D., Guzman-Novoa, E., Hunt, G.J. (2004) Defensive behavior of honey bees: organization, genetics, and comparisons with other bees. Annu. Rev. Entomol. 49, 271-298

Carlisle, T.R. (1985) Parental response to brood size in a cichlid fish. Anim. Behav. 33, 234-238

Caro, T.M. (2005) Antipredator defenses in birds and mammals. University of Chicago Press, Chicago

Clark, C.W. (1994) Antipredator behavior and the asset protection principle. Behav. Ecol. 5, 159-170

Clutton-Brock, T.H. (1991) The evolution of parental care. Princeton University Press, Princeton

Clutton-Brock, T.H., Godfray, C. (1991) Parental investment. In: Krebs, J.R., Davies, N.B. (eds.) Behavioral ecology, 3rd edn, pp. 234-262. Blackwell Scientific, Oxford

Curio, E. (1987) Brood defence in the great tit: the influence of age, number and quality of young. Ardea 75, 35-42

Dale, S., Gustavsen, R., Slagsvold, T. (1996) Risk taking during parental care: a test of three hypotheses applied to the pied flycatcher. Behav. Ecol. Sociobiol. 39, 3142

Dassow, J.A., Eichholz, M.W., Stafford, J.D., Weatherhead, P.J. (2012) Increased nest defence of upland-nesting ducks in response to experimentally reduced risk of nest predation. J. Avian Biol. 43, 61-67

Dawkins, R., Carlisle, T.R. (1976) Parental investment, mate desertion and a fallacy. Nature 262, 131-133

Dejean, A., Carpenter, J.M., Corbara, B., Wright, P., Roux, O., LaPierre, L.M. (2012) The hunter becomes the hunted: when cleptobiotic insects are captured by their target ants. Naturwissenschaften 99, 214-226

Eves, J.D., Mayer, D.F., Johansen, C.A. (1980) Parasites, predators, and nest destroyers of the alfalfa leafcutting bee, Megachile rotundata. Western Regional Extension Publication 32

Field, J. (1992) Intraspecific parasitism as an alternative reproductive tactic in nest-building wasps and bees. Biol. Rev. 67, 79-126

Garófalo, C.A., Camillo, E., Campos, M.J.O., Serrano, J.C. (1992) Nest re-use and communal nesting in Microthurge corumbae (Hymenoptera, Megachilidae), with special reference to nest defense. Insectes Soc. 39, 301-311

Gerber, H.S., Klostermeyer, E.C. (1970) Factors affecting the sex ratio and nesting behaviour of the alfalfa 
leafcutter bee. Washington Agricultural Experiment Station, Washington

Gilbert, J.D.J. (2014) Thrips domiciles protect larvae from desiccation in an arid environment. Behav. Ecol. 25, 1338-1346

Goubault, M., Scott, D., Hardy, I.C.W. (2007) The importance of offspring value: maternal defence in parasitoid contests. Anim. Behav. 74, 437-446

Hardy, I.C.W., Goubault, M., Batchelor, T.P. (2013) Hymenopteran contests and agonistic behaviour. In: Hardy, I.C.W., Briffa, M. (eds.) Animal Contests, pp. 147177. Cambridge University Press, Cambridge

Hendry, A.P., Morbey, Y.E., Berg, O.K., Wenburg, J.K. (2004) Adaptive variation in senescence: reproductive lifespan in a wild salmon population. Proc. R. Soc. Lond. B 271, 259-266

Hobbs, G.A. (1972) Beekeeping with alfalfa leafcutter bees in Canada. Bee World 53, 167-173

Hunt, G.J., Amdam, G.V., Schlipalius, D., Emore, C., Sardesai, N., Williams, C.E., Rueppell, O., GuzmánNovoa, E., Arechavaleta-Velasco, M., Chandra, S., Fondrk, M.K., Beye, M., Page Jr., R.E. (2007) Behavioral genomics of honeybee foraging and nest defense. Naturwissenschaften 94, 247-267

Kemp, W.P., Bosch, J. (2000) Development and emergence of the alfalfa pollinator, Megachile rotundata (Hymenoptera: Megachilidae). Ann. Entomol. Soc. Am. 93, 904-911

Klostermeyer, E.C., Mech Jr., S.J., Rasmussen, W.B. (1973) Sex and weight of Megachile rotundata (Hymenoptera: Megachilidae) progeny associated with provision weights. J. Kansas Entomol. Soc. 46, 536548

Koskela, E., Juutistenaho, P., Mappes, T., Oksanen, T.A. (2000) Offspring defence in relation to litter size and age: experiment in the bank vole Clethrionomys glareolus . Evol. Ecol. 14, 99-109

Miller, J.S., Rudolph, L., Zink, A.G. (2011) Maternal nest defense reduces egg cannibalism by conspecific females in the maritime earwig Anisolabis maritime. Behav. Ecol. Sociobiol. 65, 1873-1879

Minckley, R.L., Wcislo, W.T., Yanega, D. (1994) Behavior and phenology of a specialist bee (Dieunomia) and sunflower (Helianthus) pollen availability. Ecology 75, 1406-1419

Montgomerie, R.D., Weatherhead, P.J. (1988) Risks and rewards of nest defence by parent birds. Q. Rev. Biol. 63, 167-187

Morales, J., Torres, R., Velando, A. (2012) Safe betting: males help dull females only when they raise highquality offspring. Behav. Ecol. Sociobiol. 66, 135-143

Nealen, P.M., Breitwisch, R. (1997) Northern Cardinal sexes defend nests equally. Wilson Bull. 109, 269-278

Neff, J.L. (2008) Components of nest provisioning behavior in solitary bees (Hymenoptera: Apoidea). Apidologie 39, 30-45
Olendorf, R., Robinson, S.K. (2000) Effectiveness of nest defence in the Acadian Flycatcher Empidonax virescens. Ibis 142, 365-371

Orians, G.H., Pearson, N.E. (1979) On the theory of central place foraging. In: Horn, D.J., Mitchell, R.D., Stairs, G.R. (eds.) Analysis of ecological systems, pp. 155177. Ohio State University Press, Columbus

Page, R.E., Robinson, G.E. (1991) The genetics of division of labour in honey bee colonies. Adv. Insect Physiol. 23, 117-169

Parker, F.D., Frohlich, D.R. (1985) Studies on management of the sunflower leafcutter bee Eumegachile pugnata (Say) (Hymenoptera: Megachilidae). J. Apic. Res. 24, 125-131

Patterson, T.L., Petrinovich, L., James, D.K. (1980) Reproductive value and appropriateness of response to predators by white-crowned sparrows. Behav. Ecol. Sociobiol. 7, 227-231

Peterson, J.H., Roitberg, B.D. (2006) Impacts on flight distance on sex ratio and resource allocation to offspring in the leafcutter bee, Megachile rotundata. Behav. Ecol. Sociobiol. 59, 589-596

Peterson, J.H., Roitberg, B.D., Ydenberg, R.C. (2007) When nesting involves two sequential, mutually exclusive activities: what's a mother to do? Evol. Ecol. Res. 9, 1187-1197

Pitts-Singer, T.L., Cane, J.H. (2011) The alfalfa leafcutting bee, Megachile rotundata: the world's most intensively managed solitary bee. Annu. Rev. Entomol. 56, 221-237

R Development Core Team (2009) R: A language and environment for statistical computing. R Foundation for Statistical Computing, Vienna. [online] http:// www.R-project.org/ (accessed on 12 November 2010)

Redondo, T. (1989) Avian nest defence: theoretical models and evidence. Behaviour 111, 161-195

Redondo, T., Carranza, J. (1989) Offspring reproductive value and nest defense in the magpie (Pica pica). Behav. Ecol. Sociobiol. 25, 369-378

Richards, K.W. (1984) Alfalfa leafcutter bee management in western Canada. Agriculture Canada publication 1495/E. Agriculture Canada, Ottawa

Riou, S., Hamera, K.C. (2008) Predation risk and reproductive effort: impacts of moonlight on food provisioning and chick growth in Manx shearwaters. Anim. Behav. 76, 1743-1748

Rosenheim, J.A. (1990) Density-dependent parasitism and the evolution of aggregated nesting in the solitary Hymenoptera. Ann. Entomol. Soc. Am. 83, 277-286

Roubik, D.W. (2006) Stingless bee nesting biology. Apidologie 37, 124-143

Rytkönen, S., Orell, M., Koivula, K. (1995) Pseudo concorde fallacy in the willow tit? Anim. Behav. 49, 1017-1028

Schoener, T.W. (1979) Generality of the size-distance relation in models of optimal foraging. Am. Nat. 114, 902-914 
Schuett, W., Laaksonen, J., Laaksonen, T. (2012) Prospecting at conspecific nests and exploration in a novel environment are associated with reproductive success in the jackdaw. Behav. Ecol. Sociobiol. 66, $1341-1350$

Segers, F.H.I.D., Menezes, C., Vollet-Neto, A., Lambert, D., Grüter, C. (2015) Soldier production in a stingless bee depends on rearing location and nurse behaviour. Behav. Ecol. Sociobiol. 69, 613-623

Sergio, F., Bogliani, G. (2001) Nest defense as parental care in the northern hobby (Falco subbuteo). Auk 118, $1047-1052$

Sibbald, E.D., Plowright, C.M.S. (2015) Reproductive potential and its behavioural consequences in orphaned bumblebee workers (Bombus impatiens). Apidologie . doi:10.1007/s13592-015-0351-4

Stephen, W.P. (1979) A natural light Sapyga and parasite emergence trap in leafcutting bee management (Megachile rotundata). Agricultural Experiment Station. Oregon State University, Corvallis
Stokes, D.L., Boersma, P.D. (1998) Nest-site characteristics and reproductive success in Magellanic penguins (Spheniscus magellanicus). Auk 115, 34-49

Trivers, R.L. (1972) Parental investment and sexual selection. In: Campbell, B. (ed.) Sexual selection and the descent of man (1871-1971), pp. 136-179. Aldine Press, Chicago

Turillazzi, S., Hansell, M.H. (1991) Biology and social behaviour of three species of Anischnogaster (Vespidae, Stenogastrinae) in Papua New Guinea. Insectes Soc. 38, 423-437

Waters, N.D., Homan, H.W., Baird, C.R. (1980) Recognizing insect enemies of alfalfa leafcutting bees. Current Information Series No. 163, University of Idaho

Winkler, D.W., Wilkinson, G.S. (1988) Parental effort in birds and mammals: theory and measurement. In: Harvey, P.H., Partridge, L. (eds.) Oxford surveys in evolutionary biology, pp. 185-214. Oxford University Press, Oxford 